\title{
PEMODELAN IDENTIFIKASI TRAFIK BITTORRENT DENGAN PENDEKATAN CORRELATION BASED FEATURE SELECTION (CFS) MENGGUNAKAN ALGORITME DECISION TREE (C4.5)
}

Page | 1

\author{
Hesmi Aria Yanti ${ }^{1}$, Heru Sukoco ${ }^{2}$, Shelvie Nidya Neyman ${ }^{3}$
}

\author{
${ }^{1}$ Program Studi Magister Ilmu Komputer, Departemen Ilmu Komputer FMIPA IPB University \\ Jl. Raya Dramaga Kampus IPB Dramaga Bogor, West Java, 16680, Indonesia \\ ${ }^{1}$ hesmiaria11@gmail.com; ${ }^{2}$ hsrkom@apps.ipb.ac.id; ${ }^{3}$ shelvie.neyman@gmail.com
}

\begin{abstract}
Abstrak-BitTorrent merupakan protokol P2P file sharing perangkat lunak yang memungkinkan client mendistribusikan data ke client lainnya dan dapat mempengaruhi kinerja layanan jaringan. Pengambilan data trafik client BitTorrent menggunakan data sekunder yang diambil dari sumber resmi pada link https://unb.ca/cic/datasets/index.html pada tahun 2016. Data trafik digunakan sebagai model identifkasi trafik BitTorrent menggunakan correlation based feature selection (CFS) dan analisis model identifikasi trafik menggunakan Algoritme Decision Tree (C4.5). Seleksi fitur dilakukan guna membersihkan fitur-fitur yang tidak relevan sehingga dapat mempengaruhi hasil nilai accuracy. Hasil seleksi fitur didapat 7 fitur dan 1 kategori dengan 244.689 record dan identifikasi menentukan model rule tree training data dipilih empat nilai accuracy terbaik. Selanjutnya model training data dilakukan uji testing data, guna identifikasi trafik BitTorrent. Hasil uji testing data didapatlah nilai accuracy trafik BitTorrent terbaik $\mathbf{9 8 . 8 2} \%$ dengan jumlah data 73.406 record pada uji testing data $30 \%$.
\end{abstract}

Kata Kunci- algoritme C4.5, BitTorrent, correlation based feature selection, identifikasi trafik, pemodelan.

Abstract-BitTorrent is a P2P file sharing software protocol that allows clients to apply data to other clients and can affect network performance. BitTorrent client traffic data collection uses secondary data taken from official sources on the link https://unb.ca/cic/datasets/index.html in 2016. Traffic data is used as a model for BitTorrent traffic identification using feature-based correlation selection (CFS) and traffic analysis model analysis using Decision Tree Algorithm (C4.5). Feature selection is done to clean irrelevant features so that they can affect the results of the accuracy value. The results of feature selection obtained 7 features and 1 category with 244,689 records and the system connecting the rule tree data training model selected the four best accuracy values. Furthermore, the model training data is carried out by testing the BitTorrent traffic trial data. The results of data testing obtained the best BitTorrent traffic accuracy value of $98.82 \%$ with 73,406 records on the $30 \%$ data test.

Keywords - BitTorrent, C4.5 algorithm, correlation based feature selection, traffic identification, modelling.

\section{PENDAHULUAN}

Identifikasi trafik data pada layanan jaringan internet khususnya pada BitTorrent sangat dibutuhkan untuk pengelolaan dan pemantauan jaringan guna menjaga kualitas dan keamanan layanan jaringan trafik peer-to-peer $(\mathrm{P} 2 \mathrm{P})$ [1]. BitTorrent merupakan protocol $\mathrm{P} 2 \mathrm{P}$ file sharing client mendistribusikan data ke client lainnya dengan file berskala besar maupun skala kecil [2]. Identifikasi IP menggunakan port dan payload masih banyak memiliki kekurangan, sehingga alternatif yang digunakan sebelum identifikasi yaitu seleksi fitur. Metode seleksi fitur dapat meningkatkan kinerja komputasi untuk identifikasi trafik.

Fitur berbasis correlation-based feature selection (CFS) dan evaluasi konsistensi consistency-based feature selection (CON). Kemudian melakukan uji maching learning bayesian network, C4.5 decision tree, nä̈ve bayes dan naive bayes tree untuk menentukan nilai accuracy terbaik. Hasil uji accuracy dengan maching learning, didapatlah klasifikasi terbaik yaitu decision tree (C4.5) algorithm [3]. Machine learning decision tree (C4.5) algorithm, suport vector machine (SVM), naïve bayes dan random forest (RF) untuk menentukan klasifikasi trafik yang bersifat parametric. Berdasarkan machine learning untuk identifikasi trafik pada port based dalam identifikasi nomor port di header TCP jika payload tidak dienkripsi, maka identifikasi menggunakan machine learning (ML) decision tree (C4.5) algorithm sangat baik dalam menentukan model klasifikasi trafik yang bersifat parametric [4]. Selanjutnya melakukan seleksi fitur dengan membandingkan CFS, consistency-based subset evaluation (CSE) dan principal component analysis (PCA) pada trafik Botnet menggunakan algoritme decision tree (C4.5), nä̈ve bayes dan bayes network. Hasil accuracy terbaik dengan pendekatan seleksi fitur menggunakan CSE $98.24 \%$, CFS yaitu $98.18 \%$ dan PCA sebanyak $97.37 \%$ dengan klasifikasi menggunakan decision tree (C4.5). Decision trees dan regression tree (CART) algorithm digunakan sebagai 
teknik seleksi fitur Botnet $(\mathrm{P} 2 \mathrm{P})$ yang relevan. Adapun teknik menentukan fitur Botnet (P2P) yaitu dengan melakukan uji metode decision tree, principal component analysis dan Relief algorithm, dimana model neural network dengan menggunakan decision

Page|2 tree menghasilkan nilai accuracy identifikasi lebih baik yaitu nilai rata-rata $99.08 \%$ tingkat kesalahan lebih rendah positif dan dengan tingkat positif palsu $0.75 \%$ [6].

Penelitian di atas belum terdapat analisis mengenai pemodelan identifikasi trafik BitTorrent menggunakan pendekatan CFS dengan algoritme decision tree (C4.5). Penelitian ini bertujuan untuk menentukan model trafik BitTorrent dengan menggunakan pendekatan CFS dalam melakukan seleksi fitur dan menggunakan Algoritme Decision Tree (C4.5) untuk identifikasi trafik BitTorrent.

\section{METODOLOGI}

Dataset yang digunakan merupakan dataset sekunder BitTorrent, Facebook dan Youtube. Diunduh menggunakan local area network (LAN) diruang diskusi S2 Ilmu Komputer Institut Pertanian Bogor pada bulan Maret tahun 2019. Alur tahapan metode penelitian ini dapat dilihat pada Gbr. 1.

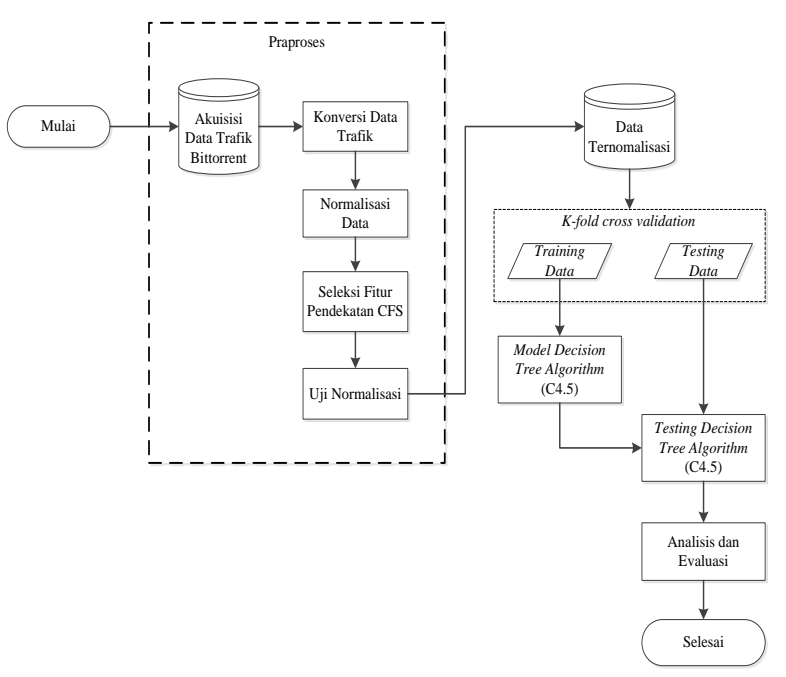

Gbr. 1 Tahapan penelitian

\section{A. Pra proses}

Tahapan pra proses yang dilakukan yaitu akuisisi data trafik BitTorrent, normalisasi data, seleksi fitur, dan uji normalisasi. Data trafik BitTorrent yang digunakan merupakan dataset sekunder Unb ISCX dengan format pcap, dataset di input dalam format query, pesan berformat query merupakan request data yang dibutuhkan. Data trafik yang sesuai akan masuk kesistem, kemudian data diolah dan data mentah dimanipulasi menjadi informasi. Kemudian data di konversi untuk selanjutnya di normalisasi data, seleksi fitur dan uji normalisasi. Penelitian ini menggunakan pendekatan CFS untuk seleksi fitur. Selanjutnya dilakukan uji normalisasi data untuk menentukan fitur yang telah diseleksi berdistribusi normal atau diambil dari data trafik yang normal.

1) Akuisisi Paket Data Trafik BitTorrent: Akuisisi paket data trafik menggunakan Wireshark dalam format pcap yang diambil berupa data trafik sekunder yang tersedia dari sumber resmi yaitu Dataset Unb ISCX pada link https://www.unb.ca/cic/datasets/url-2016.html di University of New Brunswick tahun 2016. Pemodelan yang akan digunakan pada identifikasi trafik yaitu menggunakan dataset trafik anomaly.

2) Konversi Data Trafik: Data trafik dengan format pcap dikonversi keformat .CSV file [8]. Konversi data trafik bertujuan untuk mempermudah peneliti dalam melakukan proses olah data di pemrograman $\mathrm{R}$ studio dan identifikasi trafik dalam menentukan pemodelan trafik BitTorrent.

3) Normalisasi Data: Normalisasi data merupakan proses penskalaan dataset, sehingga didapatkan nilai rentang tertentu untuk melakukan distribusi normal. Distribusi normal merupakan parameter dari simpangan baku untuk menganalisis data normal, dimana mean $=0$ dan simpangan baku $=$ 1 , format distribusi normal seperti genta (bell-sphaped) yang simetris. Distribusi normal yaitu melakukan normalisasi data terhadap data asli untuk menghasilkan nilai normal, antara dataset sebelum dan sesudah diproses menggunakan metode min-max [9]. Adapun proses normalisasi menggunakan metode min$\max (1)[10]$.

$$
x^{\prime}=\frac{x_{i}-\min (x)}{\max (x)-\min (x)}
$$

x' merupakan hasil nilai normalisasi, $\mathrm{x}_{\mathrm{i}}$ adalah fitur intence, sedangkan $\mathrm{x}$ ialah set mewakili tipe fitur, min (x) adalah nilai minimum pada fitur $x$ dan $\max (\mathrm{x})$ adalah nilai maksimum pada fitur $x$.

4) Seleksi Fitur Pendekatan CFS: Proses seleksi fitur dilakukan untuk mengurangi jumlah fitur tidak relevan yang memiliki banyak noise, missing value, inkonsentesi dan error dan mencari ciri-ciri raw data berkorelasi, mempengaruhi identifikasi trafik BitTorrent dalam menentukan pemodelan berupa nilai accuracy menggunakan metode CFS. Pengambilan data dilakukan sistem skenario rata-rata fitur dengan melakukan pengujian hipotesis univariate ( $x 1$, $\left.x 2, \ldots, x_{\mathrm{n}}\right)$ dimana sampel random dari fitur berdistribusi normal $\left(\mu, \sigma^{2}\right)$ dengan nilai fitur $\sigma^{2}$ yang sudah diketahui [11]. Sistem skenario pengambilan sampel menggunakan teknik simpel random sampling dan diambil nilai mean dapat dilihat pada (2) [12].

$$
\overline{\mathrm{x}}=\frac{\sum f_{i} x_{i}}{\sum f_{i}}
$$

$\sum$ lambang penjumlahan semua data pengamatan, sedangkan $\mathrm{f}$ frekuensi data ke-i, n banyaknya sampel 
data, $\overline{\mathrm{X}}$ merupakan nilai rata-rata sampel. Proses seleksi fitur bertujuan untuk mencari ciri-ciri yang diinginkan dari raw data, selanjutnya data akan diolah berdasarkan korelasinya. Proses ini guna memperkecil jumlah raw data dan memberikan informasi data yang

\section{Page $\mid 3$ dibutuhkan.}

Metode CFS ini adalah bagian dari metode heuristic dengan cara melihat fungsi-fungsi dari setiap fitur yang digunakan untuk prediksi kelas antar fitur dengan korelasi antar fitur. Nilai suatu subset fitur s yang terdiri dari fitur k (3) dan kriteria CFS (4) [13].

$$
\begin{gathered}
r_{s k}=\frac{k r_{c f}}{\sqrt{k+k(k-1) r_{f f}}} \\
C F S=\max _{s k}\left[\frac{r_{c f 1}+r_{c f 2}+\cdots+r_{c f k}}{\sqrt{k+k(k-1) r_{f f}}}\right]
\end{gathered}
$$

Dimana $r_{\text {sk }}$ adalah hubungan antara fitur, $\mathrm{k}$ adalah jumlah fitur sedangkan $r_{\mathrm{cf}}$ merupakan rata-rata hubungan fitur dan kelas, $r_{\mathrm{ff}}$ rata-rata korelasi antara bagian fitur dan $\max _{\text {sk }}$ adalah maksimal fitur.

1) Uji Normalisasi: Uji normalisasi diperlukan untuk menilai dataset trafik yang telah dinormalisasi berdistribusi normal atau tidak normal. Uji normalisasi dapat dilihat dengan pemeriksaan menggunakan uji shapiro-wilk atau uji w [14]. Uji normalitas statistik yang digunakan yaitu dengan asumsi jika $P$-value $<\propto$ maka tolak $\mathrm{H}_{0}$ dan sebaliknya jika $P$-value $>\propto$ gagal tolak $\mathrm{H}_{0}$, dimana $\mathrm{H}_{0}$ adalah data distribusi normal dan $\mathrm{H}_{1}$ adalah data distribusi tidak normal. Uji normalisasi data terhadap fitur-fitur yang berkorelasi dilihat menggunakan plot. Evaluasi normalisasi sampel yang lebih besar terdistribusi normal dapat dilihat dari hasil histogram atau plot Q-Q [15].

\section{B. Dataset Ternormalisasi}

Dataset ternormalisasi merupakan hasil dari proses normalisasi data trafik pada tahapan praproses, dimana dataset ternormalisasi akan digunakan sebagai implementasi uji training data dan testing data menggunakan metode $k$-fold cross validation.

1) K-Fold Cross Validation: $k$-fold cross validation merupakan implementasi uji dataset ternormalisasi. Cross validation merupakan validasi model untuk menilai keakuratan hasil analisis. Adapun dataset ternormalisasi dilakukan tahap uji testing data dan training data untuk proses klasifikasi. Dataset ternormalisasi dibagi menjadi $\mathrm{K}$ bagian yaitu $\mathrm{K}$ satu digunakan sebagai training data dan K-1 digunakan sebagai testing data [16]. Pembagian data dilakukan menggunakan $k$-fold cross validation dengan nilai $\mathrm{k}$ sama dengan 10 (5).

$$
E=\frac{1}{K} \sum_{i=1}^{k} E_{i}
$$

E merupakan data di normalisasi dan $\mathrm{K}$ jumlah pembagian/bagian. Tahap selanjutnya melakukan pembagian data kemudian diklasifikasikan menggunakan metode $k$-fold cross validation dengan nilai $\mathrm{K}=10$.

2) Pemodelan Identifikasi Trafik: Melakukan identifikasi trafik BitTorrent menggunakan sistem operasi Windows, jaringan di partisi menggunakan switch layer-3 dan data client BitTorrent diambil dari bank data sebagai model untuk identifikasi trafik. Identifikasi dalam akuisisi dataset trafik yang relevan menggunakan pendekatan CFS, CFS mengidentifikasi dan menyaring fitur yang tidak relevan, serta mengidentifikasi fitur yang relevan [17]. Paket data yang digunakan untuk identifikasi menentukan pemodelan trafik BitTorrent menggunakan Algoritme Decision Tree (C4.5).

3) Algoritme Decision Tree (C4.5): Merupakan pengembangan dari Iterative Dichotomies Algorithm (ID3). Decision tree berguna untuk mengeksplorasi data dengan menemukan hubungan yang tersembunyi antara fitur input dengan fitur target. Data input pada C4.5 algorithm berupa tabel dan menghasilkan output berupa pohon keputusan [18]. Membangun model pohon keputusan untuk pemilihan fitur menjadi node menggunakan tiga pendekatan yaitu : informasi total nilai entropy pada dataset, menghitung nilai informasi entropy dalam setiap fitur dataset, dan menghitung nilai gain pada setiap fitur dalam dataset [19]. Adapun total nilai entropy dataset diperoleh dengan cara membandingkan atau membagi jumlah keseluruhan fitur dalam dataset dengan nilai kelas atau kategori berdasarkan kriteria kemudian dikalikan dengan nilai $\log _{2 .}$. total nilai entropy dataset didefinisikan pada (6).

$$
\text { Entropy }(s)=-\sum_{i=1}^{N} P_{j} \log _{2} P_{j}
$$

$S$ adalah Jumlah total fitur dataset, $\mathrm{P}_{\mathrm{j}}$ merupakan probabilitas munculnya fitur dan $\mathrm{N}$ banyaknya fitur yang digunakan. Menghitung informasi nilai entropy pada setiap fitur dataset untuk mendapatkan informasi nilai entropy yaitu dengan menjumlahkan nilai perbandingan jumlah kelas atau kategori berdasarkan kriteria dengan jumlah data yang dimiliki sebuah fitur berdasarkan kategori, kemudian dikalikan dengan nilai $\log _{2}$. Perhitungan nilai entropy pada setiap fitur dalam dataset disebut dengan split info (7).

$$
\text { Split info }(S, A)=-\sum_{i=1}^{m} \frac{\mid S_{i} \|}{S} x \log _{2} \frac{\mid S_{i} \|}{S}
$$

$(S, A)$ Nilai entropy dari fitur berdasarkan subset fitur, $\mathrm{S}_{\mathrm{i}}$ Jumlah subset dari fitur $S$, m Jumlah subset dari fitur $S$ dan $\left|\mathrm{S}_{\mathrm{i}}\right|$ Nilai mutlak atau absolut jumlah subset. Tahap ketiga yaitu menghitung nilai gain pada setiap fitur dalam dataset (8).

$\operatorname{Gain}(S, A)=$ Entropy $-\sum_{i=1}^{n} \frac{\left|S_{i}\right|}{|S|} x$ Entropy $\left(S_{i}\right)$ 
$S$ Data sampel yang digunakan untuk training, A Atribut, $n$ banyaknya jumlah fitur, $\left|S_{\mathrm{i}}\right|$ Jumlah sampel untuk nilai v, $|\mathrm{S}|$ Jumlah seluruh sampel data, (Si) Entropy untuk sampel-sampel yang memiliki nilai i.Tahapan ketiga merupakan tahapan penyempurnaan Page | 4 terhadap definisi nilai gain menjadi nilai gain ratio (9).

$$
\text { Gain Ratio }(S, A)=\frac{\operatorname{Gain}(S, A)}{\operatorname{SplitInfo}(S, A)}
$$

Definisi nilai gain dan nilai gain ratio memiliki perbedaan, dimana ID3 algorithm nilai sebuah fitur didefinisikan dengan menjumlahkan total nilai entropy, dikurangi dengan jumlah nilai fitur yang terpilih, kemudian kategori dibagi nilai kelas fitur terpilih dari dataset, dikalikan dengan nilai entropy kelas atau kategori fitur. Sedangkan C4.5 algorithm yaitu total jumlah gain fitur dataset yang terpilih dibagi dengan total split informasi [20].

\section{Analisis dan Evaluasi}

Evaluasi kinerja berdasarkan perbandingan klasifikasi parametric nilai keakuratan terbaik yaitu machine learning Decision Tree (C4.5) Algorithm, maka untuk pengukuran menentukan klasifikasi data trafik menggunakan metode matrix. Confusion matrix dapat diartikan sebagai suatu classifier analisa dalam mengenali tuple dari kelas yang berbeda. Nilai dari True Positive (TP) dan True Negative (TN) memberikan informasi ketika classifier dalam melakukan klasifikasi data bernilai benar, False Positive (FP) dan False Negative (FN) memberikan informasi ketika classifier salah dalam melakukan klasifikasi data Tabel I [21].

TABEL I

CONFUSION MATRIX MEAMPILKAN TOTAL POSITIVE DAN NEGATIVE TUPLE

Predicted class

\begin{tabular}{|c|c|c|c|}
\hline & & Yes & No \\
\hline clas & Yes & $\mathrm{TP}$ & FN \\
\hline & No & FP & $\mathrm{TN}$ \\
\hline & Total & $\mathrm{P}^{\prime}$ & $\mathrm{N}^{\prime}$ \\
\hline
\end{tabular}

Confuison matrix merupakan metode klasifikasi yang mengandung informasi guna membandingkan hasil klasifikasi dilakukan oleh sistem dengan hasil yang relevan. Kinerja confuison matrix pada pengukuran kinerja suatu sistem klasifikasi data dapat dibagi menjadi 4 (empat) jenis yaitu klasifikasi binary, multi-class, multi-label, dan hierarchical. Pengukuran kinerja menggunakan confusion matrix, terdapat 4 (empat) istilah : True Positive (TP), True Negative (TN), False Positive (FP), dan False Negative (FN). TP,FP dan FN adalah jumlah positif yang benar, dan negative palsu sebagai representasi hasil proses klasifikasi [4].

Accuracy ialah penjumlahan dari rasio yang memiliki nilai positif benar dengan jumlah semua positif benar dan positif palsu untuk semua kelas. Matrix terakhir digunakan untuk mengevaluasi kualitas hasil identifikasi setiap kelas aplikasi dan nilai accuracy menggambarkan tingkat keakuratan sistem dalam mengklasifikasikan data secara benar (10).

$$
\text { Accuracy }=\frac{T P+T N}{T P+T N+F P+F N} \times 100 \%
$$

Penggunaan metode confuison matrix pada penelitian ini bertujuan untuk mendapatkan pemodelan identifikasi trafik BitTorrent dengan nilai keakuratan data yang baik.

\section{HASIL DAN PEMBAHASAN}

\section{A. Pra proses}

Pra proses data melakukan analisis akuisisi paket data trafik berupa raw data dalam format pcap. Dataset trafik dalam format pcap dikonversi ke format .CSV dan diberi label berdasarkan kategorinya. Data yang telah dikonversi dilakukan normalisasi data. kemudian proses seleksi fitur mengunakan pendekatan CFS. Fitur yang telah diseleksi kemudian dilakukan uji normalisasi. Hasil uji normalisasi data dapat digunakan pada training dan testing.

1) Akuisisi Paket Data Trafik BitTorrent: Akuisisi data trafik BitTorrent dilakukan pada data sekunder yang diperoleh dari raw dataset Unb ISCX. Dataset Unb ISCX di publikasikan oleh University of new Brunswick di Canada tahun 2016. Selain data trafik bittorent, akuisisi data trafik dilakukan pada beberapa data trafik lainnya diantaranya Facebook dan Youtube. Dataset trafik yang digunakan mempunyai kategori atau class target yaitu BitTorrent, Facebook dan Youtube. Jumlah paket data trafik yang didapat sebanyak 67 fitur dengan jumlah dataset pada BitTorrent 108.541 record, Facebook 1.061 record dan Youtube sebanyak 135.087 record, total dataset trafik yaitu 244.689 record. Jenis dataset trafik pada penelitian ini yaitu dalam format pcap. Kemudian untuk mempermudah proses olah data pada pemrograman $\mathrm{R}$ studio, dataset dalam format pcap dikonversi.

2) Konversi Data Trafik: Konversi data trafik digunakan untuk mengubah data format pcap data ke format .CSV. Adapun Sampling dataset trafik dengan format packet capture (pcap) dapat dilihat Gbr. 2, sedangkan sampling dataset trafik dikonversi ke format comma separted values (.csv) pada Gbr. 3.

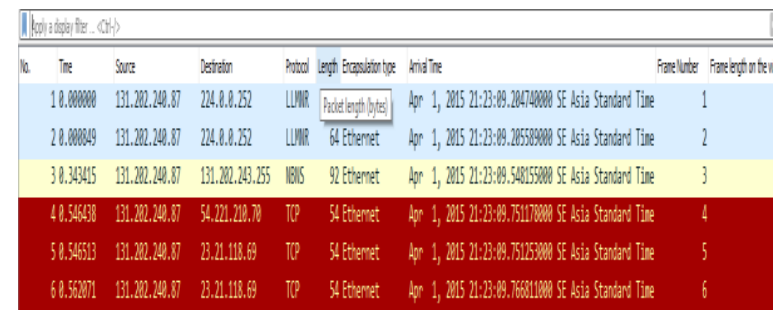

Gbr.2. Dataset trafik dengan format packet capture (pcap) 


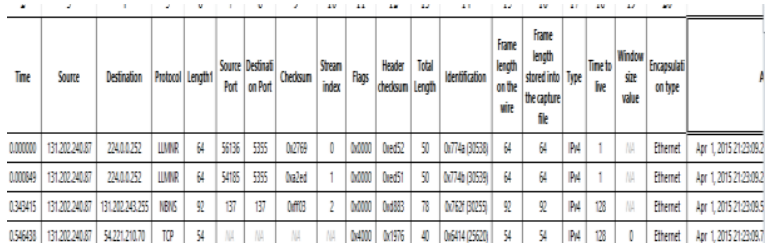

Gbr. 3. Dataset trafik dikonversi ke format comma separted values (.csv)

Pengambilan ciri dataset yang telah dikonversi ke format .CSV guna mempermudah analisa data trafik dan diidentifikasi sistem. Dataset trafik dalam format .CSV diberi label berdasarkan kategorinya. Adapun format pada dataset yaitu berupa nominal dan bilangan deskripsi, format dataset dalam bentuk bilangan deskripsi dikonversi ke bilangan nominal. Data trafik yang dikonversi yaitu sebanyak 67 fitur dan 244.689 record. Pseudocode konversi data trafik ditampilkan dibawah ini.

\begin{tabular}{l}
\hline library(forcats) \\
Dataset_trafik<-map_df(Dataset_trafik, as.numeric) \\
Dataset_trafik\$Category<- \\
as.factor(Dataset_trafik\$Category)
\end{tabular}

forcats merupakan library konversi dataset string atau karakter kedalam bentuk deskripsi. Dataset trafik kolom category berupa deskripsi dikonversi dalam bentuk nominal. Hasil konversi pelabelan pada fitur kategori trafik BitTorrent, Facebook, dan Youtube dapat dilihat pada Tabel II.

TABEL II

LABEL FITUR KATEGORI

\begin{tabular}{|c|l|c|}
\hline No & Kategori & Kode Numeric \\
\hline 1 & BitTorrent & 1 \\
\hline 2 & Facebook & 2 \\
\hline 3 & Youtube & 3 \\
\hline
\end{tabular}

Hasil konversi pada fitur katagori yaitu dari bilangan deskripsi ke bilangan nominal, diaman BitTorrent yaitu 1 (satu), sedangkan Facebook 2 (dua) dan Youtube 3 (tiga). Data trafik yang telah dikonversi lakukan normalisasi data.

3) Normalisasi Data: Data yang telah dikonversi kemudian dilakukan normalisasi, dimana jumlah record packet yang tumpang tindih mempengaruhi proses dan olah data. Plot hasil penskalaan dataset terdistribusi normal dapat dilihat pada Gbr. 4.

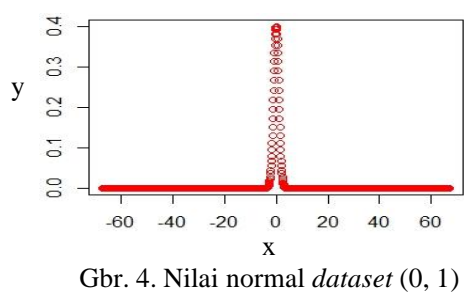

Hasil nilai normal penskalaan dataset terdistribusi normal, dimana puncak nilai $\mathrm{x}=0 . \mathrm{x}$ merupakan jumlah record packet yang terdapat pada fitur dataset. Dataset terdistribusi normal jika ukuran minimum dan rentang vektor memiliki puncak $\mathrm{x}=0$ dan 1 .
Normalisasi data untuk penskalaan dataset dapat meningkatkan performa lebih cepat karena komputasinya lebih di sederhanakan.

4) Seleksi Fitur Pendekatan CFS: Seleksi fitur dapat mempengaruhi model dan nilai accuracy, sehingga penelitian ini menggunakan sistem skenario menentukan persentase sampling yang akan digunakan. Adapun jumlah total dataset trafik pada analisis ini yaitu 244.689 record packet dan 67 fitur. Tabel III menunjukan persentase sampling dataset trafik. TABEL III

SAMPLING DATASET TRAFIK.

\begin{tabular}{|c|c|c|}
\hline No & Sampling \% & Fitur \\
\hline 1 & 0 & 20 \\
\hline 2 & 10 & 43 \\
\hline 3 & 20 & 43 \\
\hline 4 & 30 & 43 \\
\hline 5 & 40 & 43 \\
\hline 6 & 50 & 51 \\
\hline 7 & 60 & 52 \\
\hline 8 & 70 & 53 \\
\hline 9 & 80 & 53 \\
\hline 10 & 90 & 53 \\
\hline
\end{tabular}

Pengambilan dataset trafik dengan menggunakan skenario random sampling dimana data didistribusikan secara acak. Kemudian fitur yang tidak relevan dapat menyebabkan sampel bias dan mempengaruhi nilai accuracy, sehingga fitur dianggap tidak relevan dihapus [22]. Pseudocode skenario seleksi fitur dilakukan dengan menggunakan library pemrograman $\mathrm{R}$ studio.

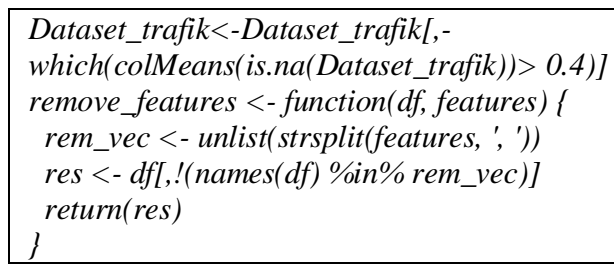

Pada Dataset_trafik dilihat rata-rata not available (NA) lebih dari 0.4 (40\%), kemudian fitur yang ratarata NA kurang dari $40 \%$ dihilangkan atau dihapus. Sedangkan pada remove_features menghilangkan feature dari data frame (parameter df), dimana feature yang akan di remove didefinisikan terlebih dahulu berdasarkan feature yang dipilih.

Hasil dari seleksi fitur trafik menggunakan skenario sampling 40\%, didapatlah 43 fitur. Berdasarkan hasil dari skenario sampling diatas masih terdapat fitur yang tidak relevan, sehinggga dilakukan penghapusan fitur secara manual. Penghapusan fitur secara manual dipilih berdasarkan hasil tampilan pada console $\mathrm{R}$ studio yang mengalami error atau tidak relevan. Hasil dari penghapusan fitur yang tidak relevan dengan mengunakan pseudocode diatas, maka didapatlah 7 fitur dengan 244,689 record. Adapun hasil dari seleksi fitur dapat dilihat pada Tabel IV. 
TABEL IV

HASIL SELEKSI FITUR

\begin{tabular}{|l|l|}
\hline \multicolumn{1}{|c|}{ Fitur } & \multicolumn{1}{c|}{ Deskripsi } \\
\hline Time & Throughput \\
\hline Source & Alamat pengirim \\
\hline Destination & Alamat tujuan \\
\hline Protocol & $\begin{array}{l}\text { Nomer dari jenis protokol yang } \\
\text { digunakan }\end{array}$ \\
\hline $\begin{array}{l}\text { Header } \\
\text { checksum }\end{array}$ & $\begin{array}{l}\text { Digunakan untuk pengecekan apabila } \\
\text { data rusak }\end{array}$ \\
\hline
\end{tabular}

\begin{tabular}{|l|l|}
\hline \multicolumn{1}{|c|}{ Fitur } & \multicolumn{1}{c|}{ Deskripsi } \\
\hline Identification & Identifikasikan paket IP \\
\hline $\begin{array}{l}\text { Protocols in } \\
\text { frame }\end{array}$ & Protokol pada paket \\
\hline
\end{tabular}

Selanjutnya fitur yang dihasilkaan digunakan untuk perhitungan korelasi antar fitur secara linier menggunakan pendekatan CFS. Hasil korelasi fitur menggunakan pendekatan CFS dapat dilihat pada Tabel V.

TABEL V

SELEKSI FITUR MENGGUNAKAN PENDEKATAN CORRELATION BASED FEATURE SELECTION (CFS)

\begin{tabular}{|l|c|c|c|c|c|c|c|}
\hline & Time & Source & Destination & Protocol & Header Check Sum & Identification & $\begin{array}{c}\text { Protocols } \\
\text { in frame }\end{array}$ \\
\hline Time & 1 & & & & & & \\
\hline Source & 0.14 & 1 & & & & & \\
\hline Destination & -0.01 & -0.90 & 1 & & & & \\
\hline Protocol & -0.22 & 0.17 & -0.23 & 1 & & & \\
\hline Header Checksum & 0.05 & -0.06 & 0.07 & -0.02 & 1 & & \\
\hline Identification & -0.13 & 0.17 & -0.19 & 0.01 & -0.43 & -0.01 & 1 \\
\hline Protocols in frame & -0.19 & 0.21 & -0.29 & 0.64 & 0.01 & & \\
\hline
\end{tabular}

Tabel V menunjukkan nilai threshold pada fitur, dimana setiap fitur memiliki korelasi negative dan positif dengan kategori atau kelas. Pemilihan fitur merupakan proses yang efektif untuk mengurangi fitur-fitur yang tidak relevan dan dapat meningkatkan nilai accuracy identifikasi trafik BitTorrent dengan menggunakan uji rata-rata info gain dan gain ratio. Dimana fitur yang paling relevan yaitu time, source, destination, protocol, header checksum, identification dan protocols in frame. Parameter untuk CFS ialah nilai threshold, nilai threshold merupakan nilai batas korelasi (minimum dari nilai symmetrical uncertainty).

5) Uji Normalisasi: untuk mendektesi data redundan, data rendundan dapat mempengaruhi hasil accuracy identifikasi trafik. Uji normalisasi dilakukan untuk menghasilkan struktur label yang normal atau tidak normal [14]. Output dari uji normalisasi menggunakan uji shapiro-wilk dan hasil seleksi fitur menggunakan pendekatan correlation matrix [1:9] yaitu $\mathrm{W}=0.91997$ dan $P$-value $=8.576 \mathrm{e}-05$, dimana $P$-value $=8.576 \mathrm{e}-05$ ialah $0.0009<0.05$, sehingga perlu dilakukan tranformasi data. Hasil transformasi data yaitu $0.00028<0.05$, dimana data tidak terdistribusi normal. Metode shapiro-wilk hanya dapat mengolah sebanyak 5000 data. Sehingga uji normalisasi dataset yang berkorelasi positif dan negatif terdistribusi normal dengan data lebih besar dapat dilihat menggunakan plot normal Q-Q. Output uji normalisasi menggunakan plot normal Q-Q dapat dilihat pada Gbr. 5

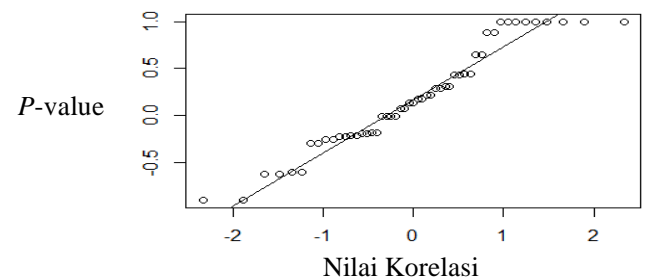

Gbr. 5. Hasil plot normalisasi
Sumbu horizontal menggambarkan nilai $\mathrm{Pi}=(\mathrm{i}-$ $0.5) / \mathrm{n}$. n adalah banyaknya dataset [23]. Hasil plot QQ pada uji normalisasi, nilai $P$-value ditempatkan pada sumbu vertikal (Y) dan nilai korelasi ditempatkan pada sumbu horizontal (X). Lingkaran tersebar mendekati garis lurus (kurva), sehingga data yang berkorelasi dapat dinyatakan terdistribusi normal.

\section{B. Dataset Ternormalisasi}

Dataset yang ternormalisasi selanjutnya digunakan sebagai training data dan testing data untuk identifikasi trafik BitTorrent dengan mengunakan $k$ fold cross validation. Fitur yang digunakan yaitu time, source, destination, protocol, header checksum, identification, protocols in frame, dan kategori dengan total paket data 244,689 record.

1) K-Fold Cross Validation: Penggunaan $k$-fold cross validation pada uji training data dan testing data menggunakan skenario pembagian training data untuk 10 folds. Pseudocode uji dataset ditampilkan dibawah ini.

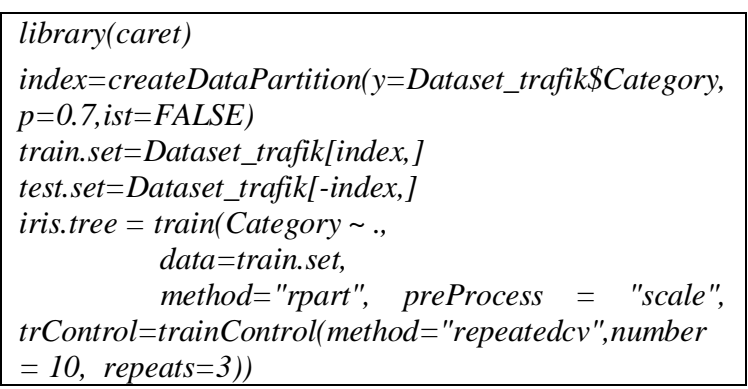

Berdasarkan pseudocode diatas package caret digunakan dalam menentukan klasifikasi dan regresi training, create data partition digunakan untuk mendapatkan sampel pada pembagian training data dan testing data secara random, berdasarkan dataset fitur category dengan menggunakan metode rpart dan dilakukan 10 folds dan 3 Epochs. Hasil uji analisis 
dengan cara sampling yaitu pembagiaan dataset training dan testing Tabel VI.

TABEL VI

SAMPLING DATA TRANING DAN DATA TESTING

\begin{tabular}{|c|c|c|c|}
\hline \multicolumn{2}{|c|}{ Sampling \% } & \multirow[b]{2}{*}{$\begin{array}{c}\text { Training } \\
\text { Record }\end{array}$} & \multirow[b]{2}{*}{$\begin{array}{l}\text { Testing } \\
\text { Record }\end{array}$} \\
\hline $\begin{array}{c}\text { Training } \\
\text { Data }\end{array}$ & $\begin{array}{c}\text { Testing } \\
\text { Data }\end{array}$ & & \\
\hline 10 & 90 & 24.471 & 220.218 \\
\hline 20 & 80 & 48.940 & 195.749 \\
\hline 30 & 70 & 73.409 & 171.280 \\
\hline 40 & 60 & 97.877 & 146.812 \\
\hline 50 & 50 & 122.346 & 122.343 \\
\hline 60 & 40 & 146.815 & 97.874 \\
\hline 70 & 30 & 171.283 & 73.406 \\
\hline 80 & 20 & 195.752 & 48.937 \\
\hline 90 & 10 & 220.221 & 24.468 \\
\hline
\end{tabular}

Dari pembagian data training dan testing, maka akan digunakan sebagai uji model untuk identifikasi trafik BitTorrent menggunakan decision tree (C4.5) algorithm.

2) Pemodelan Identifikasi Trafik: Pemodelan identifikasi trafik BitTorrent menggunakan algoritme decision tree (C4.5) diimplementasikan dengan menggunakan metode rpart pada pemrograman $\mathrm{R}$ studio dan hsil dari uji data diimplementasikan menjadi rule tree. Pseudocode pemodelan identifikasi trafik dapat dilihat dibawah ini.

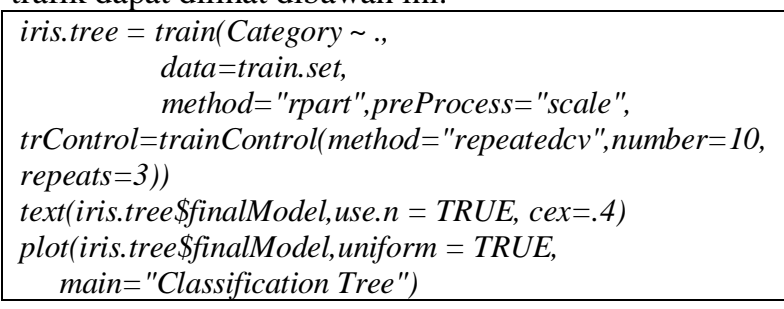

Iris.tree untuk membuat model identifikasi trafik menggunakan train.set atau training data berdasarkan category. Metode rpart 10 folds dan 3 epochs digunakan untuk mendapatkan model rule tree. Dimana persamaan (7) yaitu informasi gain, semakin tinggi nilai informasi gain maka semakin baik fitur tersebut untuk di jadikan root. Menentukan model untuk identifikasi trafik BitTorrent, dipilih berdasarkan nilai terbaik dari accuracy training data dan tesing data Tabel VII.

TABEL VII

ACCURACY TRAINING DATA DAN TESTING DATA

\begin{tabular}{|l|c|c|c|c|c|c|c|c|c|}
\hline Training Data & 10 & 20 & 30 & 40 & 50 & 60 & 70 & 80 & 90 \\
\hline Testing Data & 90 & 80 & 70 & 60 & 50 & 40 & 30 & 20 & 10 \\
\hline Accuracy & 98.40 & 98.52 & 98.61 & 98.14 & 98,60 & 98.55 & 98.61 & 98.65 & 98.57 \\
\hline
\end{tabular}

Pemilihan model dipilih dari 4 nilai accuracy terbaik yang terdapat yang terdapat pada tabel VII. Training data terbaik pertama yaitu terdapat pada training data $80 \%$ dan testing data $20 \%$ yaitu $98.65 \%$. Nilai accuracy terbaik kedua terdapat pada training data $70 \%$ dan testing data 30 nilai accuracy $98.61 \%$, selanjutnya terbaik ketiga terdapat pada training data
$30 \%$ dan testing data 70 nilai accuracy $98.61 \%$ dan nilai accuracy terbaik keempat yaitu pada training data 50\% dan testing data 50\% dengan accuracy 98.60\%. Adapun Hasil output dari nilai accuracy sebagai model traning data yang dipilih yaitu berupa tampilan rule decission tree $(\mathrm{C} 4.5)$ algorithm dapat dilihat pada Gbr.6.

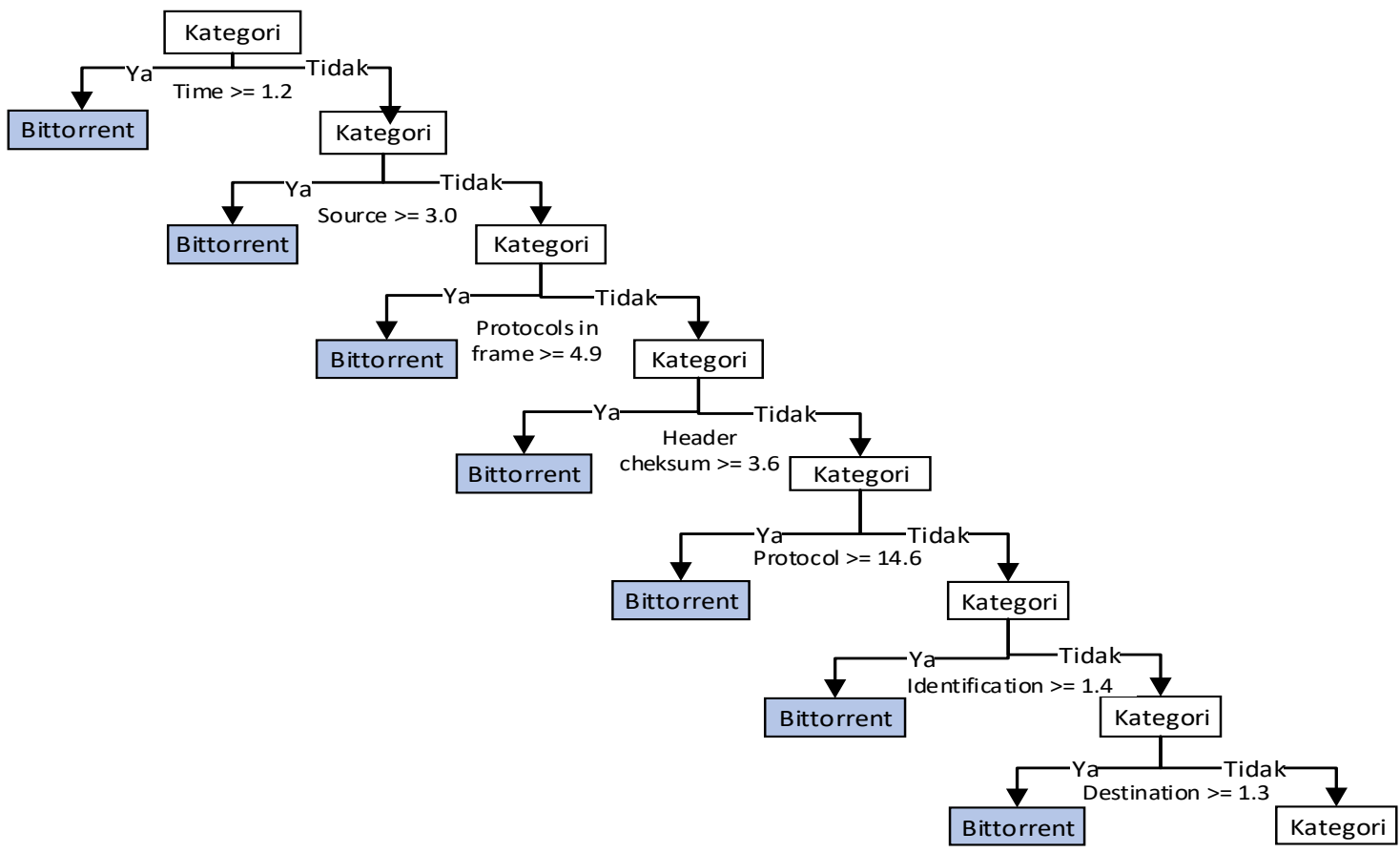

Gbr. 6. Rule decission tree (C4.5) algorithm 
Rule tree diatas merupakan hasil model training data menggunakan decission tree (C4.5) Algorithm menggunakan package rpart. Tree merupakan hasil identifikasi trafik, dimana root tertinggi terdapat pada fitur time yang merupakan throughput client mengakses BitTorrent dengan nilai 1.2 Bits Per Second (BPS). Apabila nilai time lebih dari 1.2 BPS maka dilakukan identifikasi kembali berdasarkan kategori. Selanjutnya hasil dari identifikasi trafik BitTorrent didapatlah fitur source sebagai node dengan nilai 3.0 BPS, jika lebih dari 3.0 BPS identifikasi trafik bittorent akan dilakukan pemilihan berdasarkan kategori. Selanjutnya didapatlah protocols in frame dengan nilai node $4.9 \mathrm{BPS}$, jika nilai node lebih dari 4.9 BPS maka dilakukan identfikasi kategori trafik bittorent berdasarkan node header checksum dengan nilai 3.6 BPS. Berdasarkan kategori selanjutnya berdasarkan node protocol dengan nilai 14.6 BPS, nilai node jika lebih dari 3.6 BPS maka dilakukan pemilihan fitur kategori dan didapatlah identification dengan nilai node 1.4 BPS, kemudian berdasarkan fitur destination nilai node 1.3 BPS. Hasil model trianing data kemudian digunakan sebagai analisis dan dievaluasi untuk testing data dalam menganalisis nilai accuracy model terbaik menggunakan metode confusion matrix.

\section{Analisis dan Evaluasi}

Analisis dan evaluasi terhadap uji testing data menggunakan confusion matrix untuk total positive dan negative tuple[21]. Berdasarkan hasil uji testing data, maka nilai accuracy terbaik terdapat multiclass confusion matrix yaitu 3 class $(1,2,3)$. Class 1 dan bukan class 1, antara class 2 dan bukan class 2, antara class 3 dan bukan class 3. class 1 merupakan trafik BitTorrent, class 2 Facebook dan class 3 Youtube. Adapun hasil total positive dan negative tuple pada testing data dapat dilihat pada tabel VIII.

TABEL VIII

TOTAL POSITIVE DAN NEGATIVE TUPLE PADA TESTING

\begin{tabular}{|c|c|c|c|c|}
\hline \multicolumn{5}{|c|}{ DATA. } \\
\hline Testing Data & TP & $\mathbf{T N}$ & FP & FN \\
\hline 70 & 74731 & 94466 & 1247 & 836 \\
\hline 50 & 53392 & 67503 & 878 & 570 \\
\hline 30 & 32043 & 40500 & 519 & 344 \\
\hline 20 & 21347 & 26996 & 361 & 233 \\
\hline
\end{tabular}

Tabel nilai total positive dan negative tuple pada testing data, dimana TP merupakan class positif dan TN tingkat kebenaran class BitTorrent dalam identifikasi kesalahan class. Sedangkan FP tingkat kesalahan pada class positif BitTorrent dan tingkat kesalahan class dalam identifikasi BitTorrent. Actual class merupakan kelas yang sebenarnya pada data testing, sedangkan predicted class merupakan kelas hasil prediksi dari model yang dihasilkan oleh klasifikasi. Hasil dari total positive dan negative tuple, selanjutnya dilakukan evaluasi menggunakan algoritme decision tree (C4.5) pada matrix menggunakan persamaan (9) untuk mencari nilai precision, recall (10) dan accuracy persamaan (11) pada tabel IX uji accuracy testing data

TABEL IX

HASIL EVALUASI MODEL UJI TESTING DATA

\begin{tabular}{|c|c|c|c|}
\hline $\begin{array}{c}\text { Testing } \\
\text { Data }\end{array}$ & Precision \% & Recall \% & Accuracy \% \\
\hline 70 & 98.34 & 98.89 & 98.78 \\
\hline 50 & 98.38 & 98.94 & 98.81 \\
\hline 30 & 98.41 & 98.94 & 98.82 \\
\hline 20 & 98.34 & 98.92 & 98.78 \\
\hline
\end{tabular}

Dari keempat hasil evaluasi uji testing data pada tabel 9, mendapatkan model terbaik untuk identifikasi trafik BitTorrent pada persamaan (11) yaitu terdapat pada nilai accuracy $98.82 \%$, dimana data yang digunakan sebanyak 73.406 record dengan testing data 30\%. Adapun nilai Precision persamaan (9) terbaik terdapat pada testing data $30 \%$ dengan nilai $98.41 \%$ dan nilai recall menggunakan persamaan (10) yaitu 98.94\%. Identifikasi trafik BitTorrent menggunakan CFS pada seleksi fitur dan algoritme decission tree (C4.5) dengan training data $70 \%$ dan testing data $30 \%$ dapat gunakan untuk dimplementasikan kesistem layanan jaringan internet.

\section{IV.KESIMPULAN}

Penggunaan Correlation-based Feature Selection (CFS) menentukan fitur model trafik BitTorrent sangat mempengaruhi proses olah data dan nilai accuracy identifikasi trafik BitTorrent. Hasil korelasi antar fitur memiliki nilai positif dan nilai negatif yang saling berkorelasi. Fitur yang berkorelasi digunakan sebagai training data dan testing data untuk identifikasi trafik BitTorrent menggunakan algoritme decision tree (C4.5). Hasil nilai accuracy identifikasi trafik terbaik yaitu $98.82 \%$ dengan jumlah dataset sebanyak 73.406 record pada uji testing data 30\%. Sehingga penggunaan CFS dan algoritme decision tree (C4.5) dapat digunakan dalam mengidentifikasi trafik BitTorrent berdasarkan fitur-fitur yang dipilih, diantaranya fitur time, source, destination, protocol, header checksum, identification dan protocols in frame.

Untuk penelitian selanjutnya, akuisisi dataset trafik dilakukan secara real-time dengan menggunakan metode CFS dan algoritme decision tree (C4.5). Sehingga dapat diimplementasikan ke sistem layanan jaringan internet dengan menggunakan fitur-fitur yang telah dipilih.

\section{UCAPAN TERIMA KASIH}

Terima kasih kepada IPB University yang telah mengizinkan melakukan penelitian ini dan University of new Brunswick di Canada di Kanada untuk kumpulan dataset. 


\section{REFERENSI}

[1] B. Hullar, S. Laki, and A. Gyorgy, "Early Identification of Peer-to-Peer," Traffic Machine Learning Research, vol.1, no. 1), pp. 2-7. 2011.

[2] I. Chandra., Teknik Berbagi Objek Lewat Jaringan P2P,

\begin{tabular}{l|l} 
Page 19 & Jakarta: PT Elex Media Komputindo, 2010. \\
N. Williams, S. Zander, and G. Armitage, "A Preliminary
\end{tabular} Performance Comparison of Five Machine Learning Algorithms for Practical IP Traffic Flow Classification," ACM SIGCOMM. Computer. Communication. Review, vol 36, no. 5, pp. 7-17, 2006

[4] C. Gu, S. Zhang, and Y. Sun, "Real Time Encrypted Traffic Identification Using Machine Learning," Journal of software, vol. 6, no. 6, pp. 1009-1016, 2011.

[5] P. Narang, J. M. Reddy, and C. Hota, "Feature Selection For Detection Of Peer-To-Peer Botnet Traffic," Computer. Vol. 1, no. 1, pp. 1-9, 2013.

[6] M. Alauthaman, N. Aslam, L. Zhang, R. Alasem, and M. A. Hossain, "A P2P Botnet detection scheme based on decision tree and adaptive multilayer neural networks," doi.10.1007/s00521-016-2564-5, 2016.

[7] (2016) UNB: University of New Brunswick. URL dataset. [Online]. (ISCX-URL-2016).

[8] N. Zumel, dan J. Mount., Vtreat: a data.frame Processor for Predictive Modeling, Microsoft: Preparing Data for Analysis Using R, 2016, vol. 1, no. 1, pp. 1-16.

[9] D.A. Nasution, H.H. Khotimah, dan N. Chamidah N, "Perbandingan Normalisasi Data untuk Klasifikasi Wine Menggunakan Algoritma K-NN," CESS (Journal of Computer Engineering System and Science), vol. 4, no. 1, pp. $78-82,2019$.

[10] Guntoro. (2015) Keamanan Jaringan Openflow Menggunakan Intrusion Detection System (IDS) Berbasis Backpropagation Neural Network. [Tesis]. Bogor: Institut Pertanian Bogor.

[11] S. Permana, B. Yuniarto, S. Mariyah, S. Ibnu, dan R. Nooraeni., Data mining dengan $R$ konsep serta implementasi, Bogor: In Media, 2018.
[12] N. Hartati., Statistika untuk Analisis Data Penelitian, Bandung: Pustaka Setia, 2017.

[13] Tasmi, S.A. Valianta, dan D. Stiawan, "Klasifikasi Trafik Terenkripsi Menggunakan Metode Deep Packet Inspection (DPI)," Annual Research Seminar, vol. 2, no. 1, pp. 424-429, 2016.

[14] T.J. Lorenzen, and V.L. Anderson, "Design of Experiments," A No-Name Approach, New York: Marcel Dekker, 1993.

[15] S.M. Karadimitriou. (2016) Statistical Hypothesis Testing and Normality Checking in R Solutions, Csv and Script Files. [Online]. Available: https://www.sheffield.ac.uk/polopoly_fs/1.579191!/file/stcp karadimitriou-normalR.pdf

[16] Y.M. Mahardika, A. Sudarsono, dan A.R. Barakbah, "An Implementation Of Botnet Dataset To Preddict Accuracy Based on Network Flow Model," International electronic symposiumon Knowladge creation and Intelegence Computing (IES-KCIC), vol. 1, no. 1, pp. 33-39, 2017.

[17] M. Hall., Correlation-Based Feature Selection For Machine Learning, Hamilton: The University Of Waikato, 1999.

[18] K. Izza, dan L.B. Handoko, "Implementasi dan Analisa Hasil Data Mining Untuk Klasifikasi Serangan pada Intrusion Detection System (IDS) Dengan Algoritma C4.5," Techno.Com, vol. 14, no. 3, pp. 181-188, 2015.

[19] J. Suntoro., Data Mining: Algoritma dan Implementasi dengan Pemrograman PHP, Jakarta: PT Elex Media Komputindo, 2019.

[20] H. Qian, and Z. Qiu, "Feature selection using C4.5 Algorithm for electricity price prediction," International Conference on Machine Learning and Cybernetics, IEEE, pp. 175-180, 2014

[21] J. Han, M. Kamber, and J. Pei, Data Mining: Concepts and Techniques, 3nd ed., San Fancisco: Morgan Kaufman, 2011.

[22] S. Datta, and H. Kargupta. (2014) Uniform Data Sampling from a Peer-to-Peer Network, Proceedings- International Conference on Distributed Computing Systems. [Online]. Available:.https://www.researchgate.net/publication/2214594 65 .

[23] Aunuddin., Statistika: Rancangan dan Analisis Data, Bogor: IPB Press, 2005. 